\title{
AS CRIANÇAS E AS MARCAS: QUE RELAÇÃO POSSÍVEL? UM OLHAR A PARTIR DAS MASCOTES
}

\author{
Children and brands, that relationship possible? A view from the mascots
}

\section{Los niños y las marcas: que relación posible? Una mirada sobre las mascotas}

Ana Côrte-Real ${ }^{1}$

Paulo de Lencastre ${ }^{2}$

\section{Resumo}

O presente texto tem o objetivo de apresentar as reflexões acerca das relações entre as crianças e as marcas mediadas pelas mascotes. Para tanto foram integrados os conhecimentos teóricos acerca das temáticas em questão por meio de Macklin (1996), Ji (2002), Corte Real (2007), Lencastre (1997), Perez (2011), John (1999) entre outros e dos resultados a partir da realização de grupos focais com crianças realizados na cidade do Porto em Portugal, com o objetivo de investigar três semânticas específicas: abstrato vs. figurativo, redondo vs. anguloso e simétrico vs. assimétrico. A síntese dos resultados indica que as crianças mais velhas preferem e reconhecem melhor os estímulos figurativos e, as mais novas preferem e reconhecem mais favoravelmente abstratos. Na categoria semântica redondo vs. anguloso, verifica-se que as crianças do sexo feminino reagem mais favoravelmente aos estímulos redondos e as do sexo masculino aos estímulos angulosos. Ao nível da categoria simétrico vs. assimétrico as crianças do sexo feminino preferem os estímulos simétricos e, estes são mais facilmente reconhecidos pelas crianças mais velhas; as crianças do sexo masculino preferem os estímulos assimétricos e estes são mais facilmente reconhecidos pelos novos.

Palavras-chave: marca, mascotes, crianças.

\footnotetext{
Abstract

${ }^{1}$ Doutora em Marketing pelo ISCTE/Instituto Universitário de Lisboa e Mestre em Marketing pela Universidade Católica Portuguesa. Professora do Departamento de Marketing da Universidade Católica Portuguesa, Portugal. Coordenadora do Programa Internacional MBA Atlântico (Portugal, Brasil e Angola) e dos programas Executive Master na mesma universidade. acortereal@ porto.ucp.pt

${ }^{2}$ Doutor em Gestão e Semiótica pela Universidade Católica de Louvain, Bélgica. Mestre em Gestão pela Universidade do Porto. Professor do Departamento de Marketing da Universidade Católica Portuguesa, Portugal. Professor visitante na ECA USP e na PUC SP. Pesquisador colaborador do GESC ${ }^{3}-$ Grupo de Estudos Semióticos em Comunicação, Cultura e Consumo. plencastre@porto.ucp.pt
} 
As crianças e as marcas: que relação possível? Um olhar a partir das mascotes

This paper aims to present the reflections about the relationship between children and pets mediated brands. Therefore, we integrated the theoretical knowledge about the topics concerned by Macklin (1996), Ji (2002), Royal Court (2007), Lancaster (1997), Perez (2011), John (1999) among others and results from conducting focus groups with children conducted in the city of Porto in Portugal, aiming to investigate three specific semantics: abstract vs. figurative, vs round. vs. angular and symmetrical. asymmetrical. A summary of the results indicates that older children prefer and better recognize the stimuli and figurative, the newest recognize and prefer more abstract favorably. In round vs. semantic category. angular, it appears that the female children react more favorably to the stimulus round and the male to stimuli angular. At the category level vs symmetrical. Asymmetric female children prefer symmetrical stimuli, and these are more easily recognized by older children, children prefer male asymmetric stimuli and these are more easily recognized by the new.

Keywords: brand, mascots, children.

\section{Resumen}

Este trabajo tiene como objetivo presentar las reflexiones sobre la relación entre los niños y las marcas mediados por las mascotas. Por lo tanto, hemos integrado los conocimientos teóricos sobre los temas en cuestión por Macklin (1996), Ji (2002), Royal Court (2007), Lencastre (1997), Pérez (2011), John (1999) entre otros y los resultados a partir de la realización de grupos focales con niños llevados a cabo en la ciudad de Oporto, en Portugal, con el objetivo de investigar tres semánticas específicas: Abstracto vs figurativo, redondo vs angular y simétrica vs asimétrica. Un resumen de los resultados indica que los niños mayores prefieren y reconocem mejor los estímulos figurativos y los más nuevos prefieren y reconocen mejor lo más abstracto. En la categoría semántica redonda vs. angular, parece que las niñas reaccionar más favorablemente a la redonda de estímulo y los niños a estímulos angulares. En la categoría de nivel simétrico vs. asimétrico niñas prefieren estímulos simétricos, y éstas son más fácilmente reconocibles por los niños mayores, los niños prefieren estímulos asimétricos y estos son más fáciles de reconocer por los más jovenes. Palabras-clave: marca, mascotas, niños.

\section{AS CRIANÇAS E AS MARCAS}


Para as crianças as marcas são provavelmente o aspeto mais relevante dos mercados (John, 1999). As crianças adquirem informação relativa ao mercado por observação e participação (aprendizagem acidental) e por instrução. Num dos estudos pioneiros neste domínio, Guest (1942) verificou que as crianças entre os 7/8 anos de idade sabem um elevado número de nomes de marcas.

Mesmo antes de saberem ler, as crianças, já são capazes de reconhecer as embalagens e as marcas. Em idade pré-escolar as crianças demonstram competências para recordarem nomes de marcas, sobretudo se forem fornecidas pistas visuais, como cores, imagens ou mascotes (Macklin, 1996).

À medida que as crianças crescem a notoriedade das marcas aumenta. Por um lado, a crescente capacidade das crianças reterem as marcas está diretamente associada à sua idade. Por outro lado, a notoriedade das marcas desenvolve-se primeiro nas categorias de produtos direcionados para as crianças, como os cereais, snacks e brinquedos e, mais tarde para produtos direcionados para adultos (John, 1999).

As crianças veem as marcas como algo necessário, inerente ao mercado e fundamentais para identificar a oferta: "tudo tem que ter marca", "não existem coisas sem marcas" (expressões obtidas em focus groups de crianças conduzidos pela autora, Côrte-Real, 2007). A percepção das marcas como algo de verdadeiro pode ser ilustrada a partir da relação que as crianças estabelecem com as marcas de "amor verdadeiro" (Ji, 2002): "eu sei que tudo que é Nike é bom, por exemplo, eu já tive sapatilhas de outras marcas, e as da Nike não têm comparação, são muito melhores".

Para as crianças as marcas são caras. Esta associação ilustra a dimensão do conhecimento simbólico das marcas (John, 1999) refletindo de alguma forma a marca como algo de aspiracional. De acordo com Ji (2002) a associação expressa a relação metafórica que as crianças estabelecem com as marcas, denominada de "admirador secreto". As crianças admiram as marcas, elas são boas e caras: "quando for grande quero ter um Jeep como o meu pai, mas como é uma marca muito cara, tem que ser quando eu for bem mais velho".

Menos frequente, mas revelador é o fato de que para algumas crianças as marcas representarem uma troca justa, value for money: "existem marcas que são boas e não são caras, como a Zara". Esta associação reflete uma relação com a marca do tipo "bons amigos" (Ji, 2002), uma marca em quem se pode confiar. 
As crianças e as marcas: que relação possível? Um olhar a partir das mascotes

No âmbito das associações menos favoráveis, algumas crianças veem as marcas como exploradoras, falsas, que enganam, que no fundo não cumprem a sua promessa: "às vezes as coisas têm marcas e são más". Esta é uma associação que reflete a visão das marcas como "inimigas" (Ji, 2002), as marcas que defraudam as expectativas.

\section{AS CRIANÇAS E AS MASCOTES}

As mascotes representam um tipo especial de sinais do mix de identidade das marcas que possui características humanas ou animais. A sua função é antes de mais afetiva, na medida em que dão vida anímica às marcas, potencializam o seu consumo e criam vínculos de relação durável sustentada em emoções (Perez, 2011).

As mascotes são também úteis para criar notoriedade porque, como são ricas em imagens e cor, captam a atenção do consumidor (Keller, 2008). Além do mais, as mascotes da marca podem ajudar a comunicar atributos chave do produto/organização. Se os consumidores tiverem um sentimento forte em relação a uma mascote irão muito provavelmente criar percepções favoráveis acerca dos produtos ou organização com os quais aquela mascote está associada.

A atitude das crianças face ao consumo goza de uma predominância do registo afetivo: primeiro a criança gosta, depois formula o pedido e no final retém a alteração cognitiva. Esta questão é determinante ao nível da comunicação da marca. As mascotes são assim um símbolo visual da marca particularmente importante no segmento das crianças, uma vez que permitem que elas estabeleçam uma ligação emocional com a marca, e porque simultaneamente, favorecem a sua memorização.

Existem diferentes tipos de mascotes, bem como diferentes estratégias face à sua denominação. Os nomes das mascotes podem ser iguais ao nome da marca, podem ter um nome que faça alguma referência à marca sem ser exatamente igual, ou optarem por ter um nome completamente diferente da marca.

No que respeita à tipologia das mascotes ela é muito variada. No entanto, criamos uma taxionomia que não ambiciona de forma alguma a exaustividade da análise dos diferentes tipos de mascotes, mas permite perceber as principais decisões a tomar quando uma marca pretende adotar este sinal.

As mascotes são um tipo especial de personagens da marca. As personagens da marca podem ser celebridades (como, por exemplo, Cristiano Ronaldo para Portugal ou, 
As crianças e as marcas: que relação possível? Um olhar a partir das mascotes de Ana Côrte-Real e Paulo de Lencastre

Ana Paula Arósio, para o Brasil) ou serem personagens criadas pela marca. No âmbito das personagens criadas, elas podem ser pessoas reais (a Marta da Ok Teleseguro, o Garoto Bombril - o ator Carlinhos Moreno), pessoas desenhadas (Betty Crocker), ou imaginárias que denominaremos mascotes.

Dentro das mascotes, ou seja, das personagens criadas e imaginárias antropomórficas, elas podem ser mais próximas da figura humana, e assim as designamos de mascotes humanóides (Ronald McDonald), de figuras animais (Tigre Tony da Frosties - Sucrillos) ou baseadas na antropomorfização de produtos (Chiquita Banana). Esta taxionomia é representada na figura seguinte:

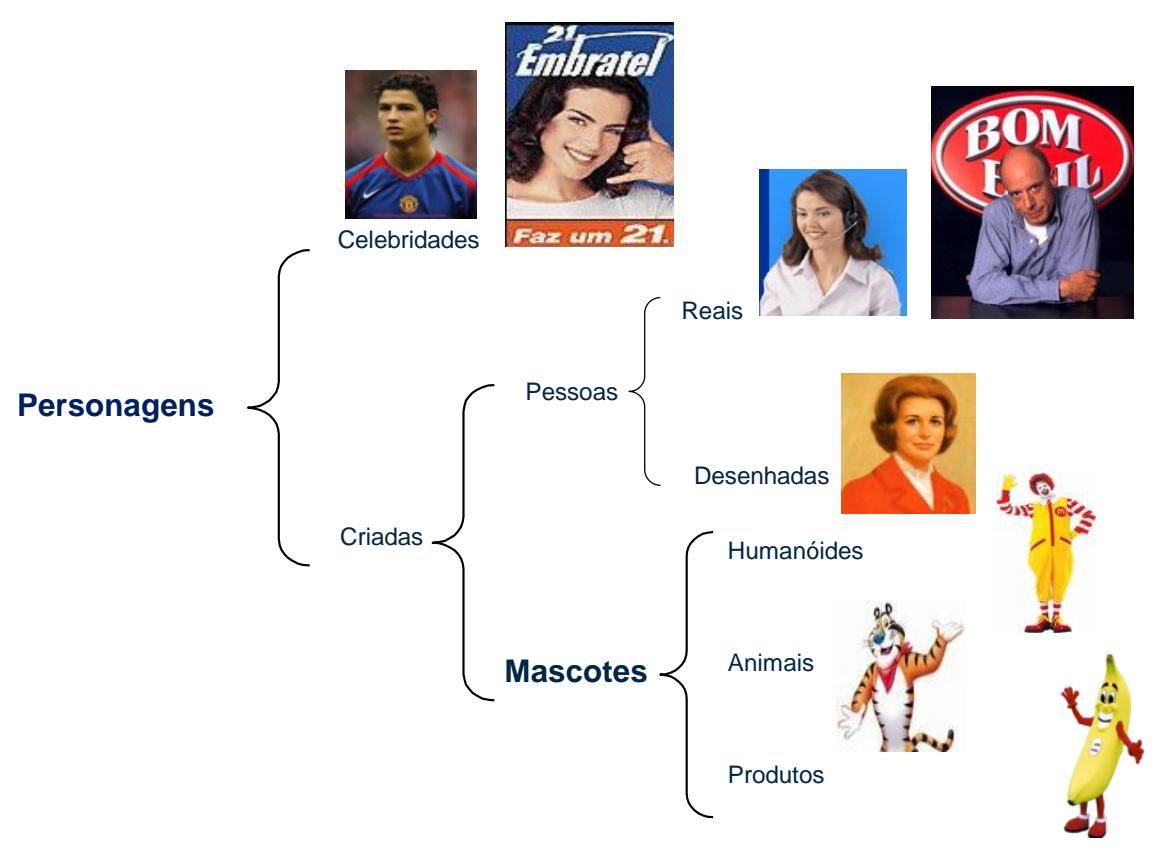

Fig. 1 - Taxionomia das personagens da marca. Adaptado de Côrte-Real (2007)

As mascotes sendo uma personagem criada, desde logo detêm determinadas vantagens face às celebridades. Vejamos algumas delas a seguir.

Primeiro, ao criar-se uma personagem, os marketeers têm a liberdade de criar as suas características individuais, enquanto as celebridades já detêm os seus traços, não permitindo a manipulação pela marca. Nas personagens criadas, os marketeers podem desenhar especificamente os traços portadores dos atributos desejados. 
As crianças e as marcas: que relação possível? Um olhar a partir das mascotes

Em segundo lugar, enquanto as celebridades frequentemente caucionam mais do que uma marca, as personagens criadas são quase sempre concebidas para caucionar um único produto ou uma única marca. Um dos princípios da eficácia das personagens depende da sua congruência com o(s) produto(s) caucionado(s). Esta congruência é geralmente superior quando a personagem é criada.

Nesta situação de criação de uma mascote, devemos perceber que para as crianças as mascotes são "bonecos", engraçados, divertidos, meigos, que podem ser "meios homens, meios bonecos". Efetivamente são sinais que não provocam muitas associações negativas, embora o seu impacto dependa das características de design que apresentam e do segmento a que se destinam.

Assim e de um ponto de vista do marketing, é importante perceber que as marcas podem não agir, pensar ou sentir, no entanto as mascotes contribuem para que elas se tornem vivas. Importa por isso aceitar a dimensão comportamental a que as mascotes são associadas, na medida em que se o fizermos estaremos necessariamente a fortalecer a relação das marcas com as crianças.

Para que este resultado ocorra é importante não esquecer que as características de design das mascotes influenciam as respostas obtidas, que por sua vez também dependem da idade e do gênero da criança.

Apresentamos aqui os resultados mais relevantes no que respeita a 3 categorias semânticas particularmente analisadas na pesquisa em estética experimental: abstrato vs. figurativo, redondo vs. anguloso e simétrico vs. assimétrico.

1. As crianças mais velhas preferem e reconhecem melhor os estímulos figurativos e, as mais novas preferem e reconhecem mais favoravelmente abstratos, sendo o género da criança relativamente indiferente;

2. No que respeita à categoria semântica redondo vs. anguloso, verifica-se que as crianças do sexo feminino reagem mais favoravelmente aos estímulos redondos e as do sexo masculino aos estímulos angulosos;

3. Ao nível da categoria simétrico vs. assimétrico as crianças do sexo feminino preferem os estímulos simétricos e, estes são mais facilmente reconhecidos pelas crianças mais velhas; as crianças do sexo masculino preferem os estímulos assimétricos e estes são mais facilmente reconhecidos pelos novos. 
As crianças e as marcas: que relação possível? Um olhar a partir das mascotes de Ana Côrte-Real e Paulo de Lencastre

Numa análise conjunta representada na figura 2 verificamos que o abstrato é mais jovem, o figurativo é mais adulto; o redondo é mais feminino, o anguloso é mais masculino. Em termos afetivos o simétrico é mais feminino, o assimétrico é mais masculino; mas em termos cognitivos, o simétrico é mais adulto e o assimétrico é mais jovem.

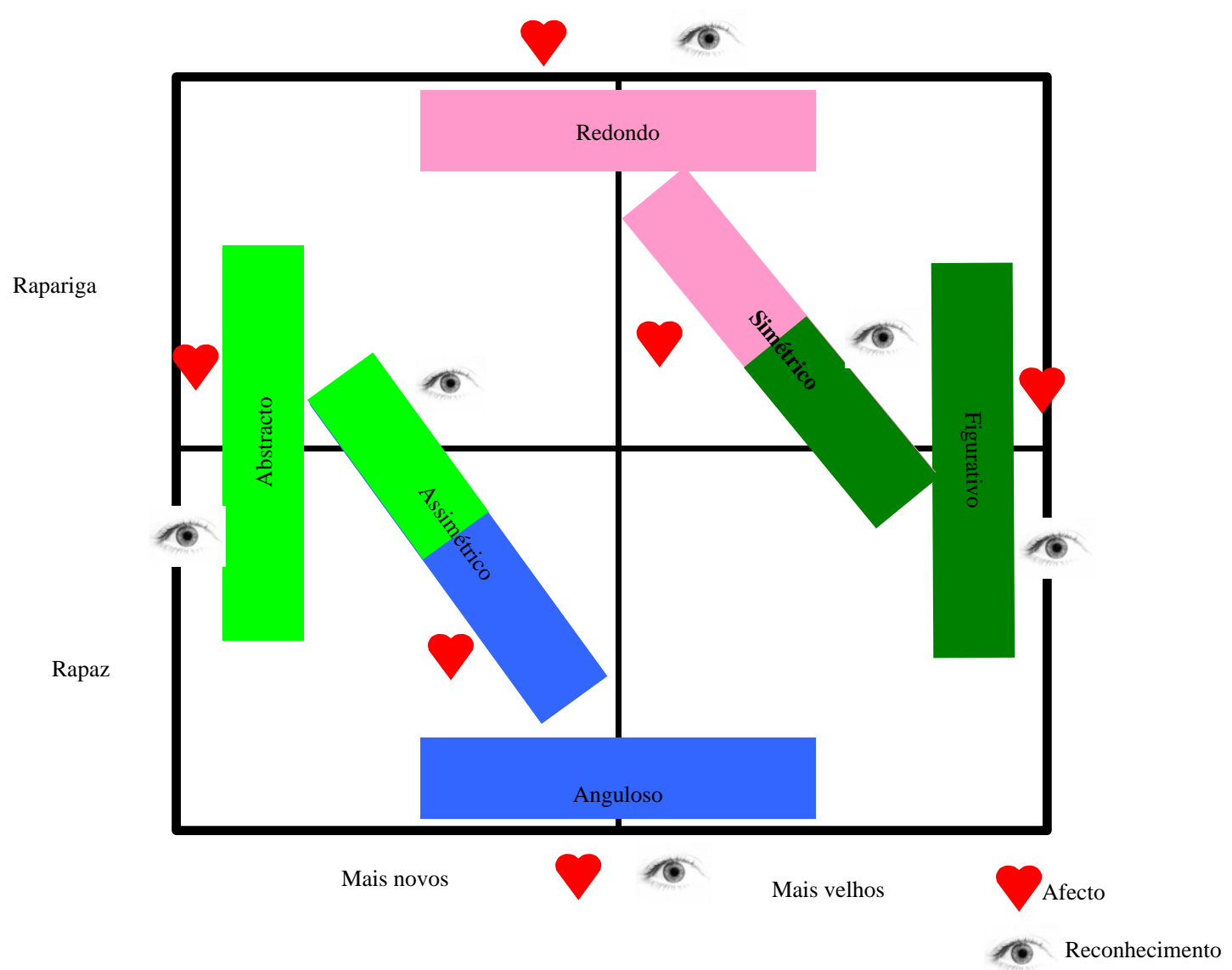

Fig. 2 - A atitude das crianças face às características de design. Côrte-Real, 2007

Podemos perceber que a clássica vantagem da figuratividade (Lencastre, 1997), e também da simetria, apenas se acentuam com o evoluir da idade, pelo que as crianças mais jovens aceitam muito bem as mascotes mais abstratas e assimétricas.

Podemos também perceber que as crianças do sexo feminino estão mais próximas do ideal clássico, associado à simetria, ao equilíbrio, à harmonia e suavidade. Por sua vez as crianças do sexo masculino aceitam mais favoravelmente as formas associadas ao conflito, à dureza, as formas que criam maior agitação e tensão.

\section{ORIENTAÇÕES PARA A PRÁTICA DAS MARCAS}


Da pesquisa realizada podemos concluir algumas grandes orientações para a prática da utilização das mascotes na comunicação das marcas com as crianças:

1. As crianças são especiais, são exigentes como consumidoras, sensíveis às marcas, entendem-nas e classificam-nas: umas marcas tornam-se amigas, outras admiradas, outras são consideradas justas, mas algumas, as que defraudam as expectativas, são inimigas.

2. O desafio do marketing infantil está relacionado com o facto de a criança centrar toda a sua resposta num único estímulo. Se gostarem desse estímulo, desenvolvem uma resposta favorável à marca; no caso contrário, rejeitam-na. A questão que se coloca é: qual será o estímulo? a embalagem? a cor? o nome da marca? o produto em si? a mascote? ...

3. As mascotes das marcas são o sinal mais relevante da marca junto do target infantil. No entanto o seu impacto depende das características de design das mascotes e do segmento a que se destinam, nomeadamente o género e a idade.

4. O abstrato é mais jovem, o figurativo é mais adulto. O redondo é mais feminino, o anguloso é mais masculino. Em termos afetivos o simétrico é mais feminino, o assimétrico é mais masculino; mas em termos cognitivos, o simétrico é mais adulto e o assimétrico é mais jovem.

\section{REFERÊNCIAS BIBLIOGRÁFICAS}

CÔRTE-REAL, Ana (2007), As Atitudes das Crianças face às Mascotes das Marcas. Lisboa: Instituto Universitário de Lisboa, Tese de Doutoramento.

Guest, Lester P. (1942), The Genesis of Brand Awareness, Journal of Applied Psychology, 26: 800-808.

JI, Mindy F. (2002), Children's Relationships with Brands: “True Love” or "One Night Stand"?, Psychology \& Marketing, 19 (4): 369-387.

JOHN, Deborah R. (1999), Consumer Socialization of Children: A Retrospective Look at Twenty-Five Years of Research, Journal of Consumer Research, 26 (3): 183-213.

KELLER, Kevin L. (2008), Strategic Brand Management: Building, Measuring and Managing Brand Equity, Upper Saddle River: Prentice-Hall. 
As crianças e as marcas: que relação possível? Um olhar a partir das mascotes de Ana Côrte-Real e Paulo de Lencastre

LENCASTRE, Paulo de (1997), L`Identification de la Marque, un Outil de Stratégie Marketing: le Lom de la Marque, le Logotype et la Mémorisation (A Identificação da Marca, um Instrumento da Estratégia de Marketing: o Nome da Marca, o Logotipo e a Memorização), Louvain-la-Neuve: Université Catholique de Louvain, Tese de Doutoramento.

MACKLIN, M. Carole (1996), Pre-schooler Learning of Brand Names from Visual Cues, Journal of Consumer Research, 23: 251-261.

PEREZ, Clotilde (2011), Mascotes: Semiótica da Vida Imaginária, São Paulo: Cengage Learning.

Artigo recebido: 04/2012

Artigo aprovado: 06/2012 